\title{
The Delineation of Groundwater and Geotechnical Parameters within Marmara Area of Chikun Local Government of Kaduna State, Nigeria
}

\author{
N. Kure ${ }^{\mathrm{a}, *}$, I. H Daniel ${ }^{\mathrm{a}}$, C. G. Afuwai ${ }^{\mathrm{a}}$, E. J. Adoyi ${ }^{\mathrm{a}}$, I. A. Bello ${ }^{\mathrm{b}}$ \\ ${ }^{a}$ Department of Physics, Kaduna State University, Kaduna, Nigeria \\ ${ }^{b}$ Division of Agricultural Colleges, Ahmadu Bello University, Zaria, Nigeria
}

\begin{abstract}
Geophysical investigation for engineering studies was carried out around Faith Academy, Marmara village, Kaduna within the basement complex of North-Western Nigeria. Six (6) Vertical Electrical Sounding (VES) were established using Schlumberger configuration. The geoelectric section revealed five subsurface layers defined by the topsoil, which comprises humus, clay and laterite; followed by weathered layer which comprises of sandy soil, fractured layer which constitutes of coarse grain sands and gravels and fresh basement which is porphyritic granite. The resistivities and thicknesses of the topsoil range from $47-4212 \Omega m$ and $2-5 m$ respectively. The weathered/fractured basement has average thickness of $42 \mathrm{~m}$ with resistivity ranging from $350-774 \Omega \mathrm{m}$. The Areas found to meet the conditions of high basement resistivity and shallow depth to basement, are found to be at VES A1, A2, A3, A4 and A6. Hence, VES A1 have been found to be the competent zones within the study area, and are good for the construction of high-rise buildings, roads and bridges. VES A3, A4 and A6 are areas that do not meet the conditions for construction of a high-rise buildings. However, VES A3, A4 and A6 appears to be viable for groundwater exploration with aquifer thickness ranges between $18-42 m$ and depth ranges of $6-10 m$, while the average depth to fresh basement is $43 m$.
\end{abstract}

Keywords: Geotechnical, Resistivity, Chikun, Topsoil/Laterite, Aquifer

Article History :

Received: 13-03-2019

Received in revised form: 26-03-2019

Accepted for publication: 27-03-2019

Published: $30-03-2019$

(c)2019 Journal of the Nigerian Society of Physical Sciences All Rights Reserved. Communicated by: O. J. Abimbola

\section{Introduction}

The development of technology has made the quest for water for all purpose in life to drift from ordinary search to prospecting to steady and reliable subsurface or groundwater from boreholes. In Nigeria, presently, borehole has rescued the citizenry from acute shortage of water.

The geoelectric method has been found to be very reliable for groundwater studies over the years. The geotechnical evaluation of subsurface condition of a site is necessary in generating

\footnotetext{
${ }^{*}$ Corresponding Author Tel. No: 09036041268

Email address: nicodemus.kure@kasu.edu.ng (N. Kure )
}

relevant data inputs for the design, and construction of structures and boreholes [1]. The search for groundwater dates back to history. This is because, of all the natural resources, water permeates perhaps must deeply into the all aspect of our life. Thus, water is essential to life. Its presence or lack of it determines, to great extent, the nature of the natural environment in which we live and majority of our economic activities depend on it. The development and utilization of groundwater resource therefore becomes very imperative [2,3].

Due to the collapse of bridges, buildings and other structures in Nigeria, there are needs to provide information on the subsurface sequence and structural disposition necessary for the 
buildings. Detailed geophysical and geotechnical investigation provides such information to provide adequate solution to prevention against future occurrence. Furthermore, lack of proper soil investigation and interpretation of sites conditions amongst the causes that may pose danger to the existing structures in Nigeria.

The importance of geological exploration methods, as means of exploring the groundwater and zones for engineering structures such as high rising building and bridges cannot be over emphasized. Methods including Vertical Resistivity Sounding (VES), Seismic Refraction, Horizontal Profiling (Wenner) and Very Low Frequency (VLF) have been successfully used to explore for groundwater $[4,5]$.

The Vertical Electrical Sounding is a Direct Current Resistivity tool of geophysics for the determination of the subsurface of a place. It has been used extensively for the determination of the aquifer potential for the drilling of boreholes. These days, it is used for in-depth geotechnical studies to determine the suitability of a site for the building of heavy structures including high rise buildings, bridges, and stadia. Hence, the method can be used in the study of subsurface layering of a place, to provide information that will help in determining the nature of soil at the site and its stratification, selecting the type and depth of foundation problems (e.g. expansive soil and collapsible soil) and determining the depth and nature of bedrock, if and when encountered.

In this work, D.C resistivity method-considered to be the quickest and the most economic technique, using VES- will be used to provide information on the zone.

\section{Theory}

The theoretical study of the earth resistivity methods is to consider the case of completely homogenous isotropic medium. The equation which gives the potential due to a single point source of current at surface can be deduced from two basic equations; ohm's law and divergence condition. The ohm's law is given as:

$$
\Delta \cdot J=0
$$

The potential due to a single point source of current at earth surface is given as:

$$
U=\frac{\rho I}{2 \pi r}
$$

where $\rho$ denotes the earth density, $I$ is the Current, $2 \pi$ is a Constant, and $r$ is Resistance. The current $I$, is passed through current electrode $C_{1}, C_{2}$ as shown in figure below (Figure 1): The potential difference at $\mathrm{M}$ is

$$
U_{m}=\frac{I \rho}{2 \pi}\left[\frac{1}{r_{1}}-\frac{1}{r_{2}}\right] .
$$

The potential difference at $\mathrm{N}$ is

$$
U_{n}=\frac{I \rho}{2 \pi}\left[\frac{1}{r_{3}}-\frac{1}{r_{4}}\right] \text {. }
$$

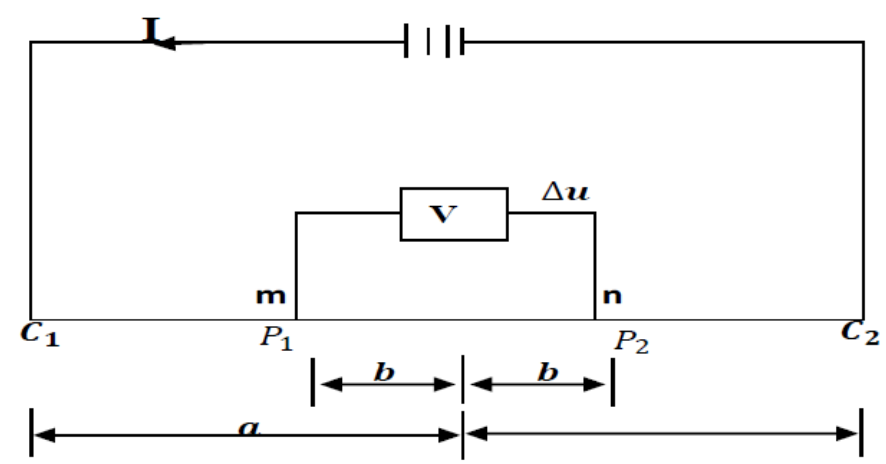

Figure 1. General four electrode configuration for resistivity measurement.

The difference in potential at $\mathrm{M}$ and $\mathrm{N}$ is given as $\Delta U=U_{m}-U_{n}$

$$
U_{n}=\frac{I \rho}{2 \pi}\left[\frac{1}{r_{3}}-\frac{1}{r_{4}}-\frac{1}{r_{3}}+\frac{1}{r_{4}}\right] .
$$

Hence, the resistivity is given by

$$
\rho_{a}=\frac{\Delta U}{I}\left[2 \pi\left\{\frac{1}{r_{3}}-\frac{1}{r_{4}}-\frac{1}{r_{3}}+\frac{1}{r_{4}}\right\}\right] .
$$

Let $K=2 \pi\left\{\frac{1}{r_{3}}-\frac{1}{r_{4}}-\frac{1}{r_{3}}+\frac{1}{r_{4}}\right\}$, therefore,

$$
\rho_{a}=K R
$$

where, $K$ is a Geometric factor and $R=\Delta U / I$.

\section{Methodology}

\subsection{Geology of the study area}

Marmara is a settlement of Chikun Local Government Area of Kaduna State, Nigeria. It is located geographically between latitude $10^{\circ} 3^{\prime}$ and $10^{\circ} 50^{\prime} \mathrm{N}$ and longitude $6^{\circ} 4^{\prime}$ and $7^{\circ} 5^{\prime} \mathrm{E}$ as shown in Figure 2. Chikun Local Government Area of Kaduna State geographically is in the North-West part of Nigeria which is part of West Africa Zone. These unconsolidated materials are known to reflect some dominant hydrologic properties, and the highest groundwater yields in Basement complex area found in areas of thick overburden overlying fractured zones and are characterized by relatively low resistivity [6]. Groundwater occurrence in the area could be grouped into three; the weathered/fractured basement complex, newer basalts and river alluvium. Climate and vegetation of study area has a typical savannah climate with distinct wet and dry seasons, the wet season ranges from April to October, while the dry season between end October to March, the average annual rainfall for Kaduna is $300 \mathrm{~mm}$. Rainfall generally reaches its peak in August and it has a characteristic mean annual temperature of $29^{\circ} \mathrm{C}$ in March/April. The dominant River Kaduna controls the course of most of the rivers and streams in the area [7] 


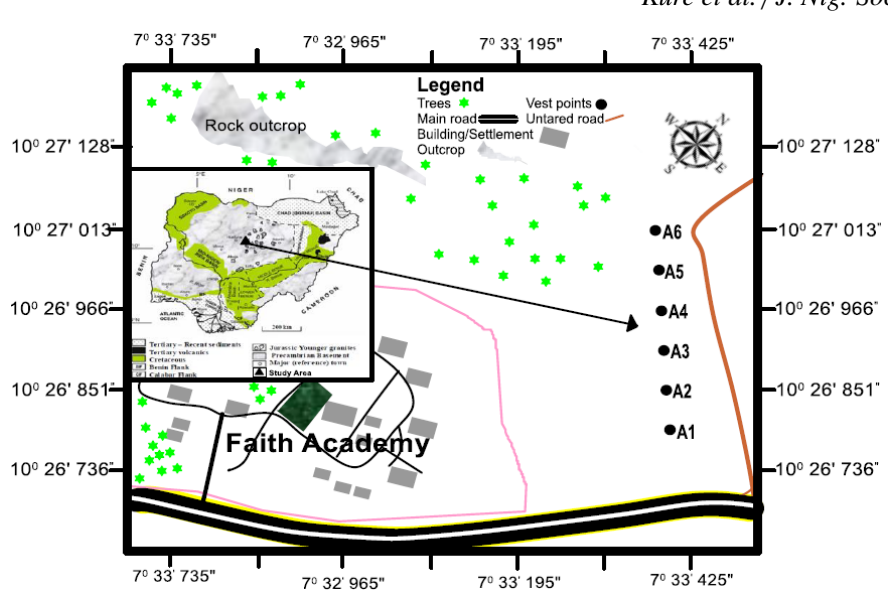

Figure 2. Map of the Study Area showing all the VES Stations

\subsection{Materials and method}

The basic requirement used for the study is Ohmega Resistivity Meter which displays resistance value digitally as computed from Ohm's law. The Ohmega Resistivity Meter is powered by a 12.5 Volts, D.C. power source. Other materials that accompany the equipment are, two measuring tapes, four hammers, thirty steel electrodes and four connecting wires (cables) for current and potential electrodes and a Global Positioning System (GPS).

Generally four-electrode array are used at the surface, one pair for introducing current into the earth and the potential difference these established are measured in the vicinity with the second electrode pair. Large numbers of electrode arrangement have been used for resistivity exploration[5]. Any of these can be used for lateral variation of resistivity or vertical variation of resistivity as a function of the current depth. In resistivity method, current are driven into the ground. Any variation of subsurface resistivity $(\rho)$ alter the current flow which in turn affects the distribution of electric potentials. The potential, these established, are measured at the surface. Deviation of these pattern of potential difference from uniform earth represent the geological features of resistivity exploration.

\subsection{Choice of electrode configuration}

The choice of a configuration for prospecting is dependent on a number of factors amongst which are the type of investigation required, the terrain of the area of the investigation, and the position of the suspected geological structure. In vertical electrical sounding (VES) measurement, the centre of the electrode spread remains fixed but the separation of electrodes is progressively increased, hence choice of Schlumberger configuration (Figure 1), this configuration is therefore more cost effective since it saves time and manpower[1].
Applying equations 5 and 6 to the above array gives

$$
\begin{aligned}
K & =2 \pi /\left\{\frac{1}{a-b}-\frac{1}{a+b}-\frac{1}{a+b}+\frac{1}{a-b}\right\} \\
K & =\pi /\left\{\frac{1}{(a-b)}-\frac{1}{a+b}\right\} \\
K & =\pi /\left\{\frac{a^{2}}{2 b}-\frac{b}{2}\right\},
\end{aligned}
$$

therefore,

$$
\rho_{a}=\pi /\left\{\frac{a^{2}}{2 b}-\frac{b}{2}\right\} \Delta / I
$$

where,

- $a=$ separation between current electrode at the centre of the configuration,

- $b=$ separation between potential electrode at the centre of the configuration, and

- $\rho_{a}=$ apparent resistivity of the earth for a Schlumberger array.

This last expression gives the approximate relationship between the apparent resistivity $\rho_{a}$, and the approximate resistivity value term usually given by terrameter during field measurement. The coefficient of $\Delta U / I$ is the geometric factor which is characteristics of the spread used. The electrical resistivity data was acquired with ABEM terrameter SAS 300 along with other equipment cables and electrodes.

Table 1. Resistivity Range of some Rock Types (Compiled from $[2,4,9,10])$

\begin{tabular}{rr}
\hline Rock type & Resistivity $(\Omega-M)$ \\
\hline Topsoil/clay/silt & $65-200$ \\
Laterite/Indurated Laterite & $45-800$ \\
Weathered Basement & $2-220$ \\
Fractured basement & $218-520$ \\
Fresh basement & $<1000$ \\
\hline
\end{tabular}

\subsection{Data Interpretation}

The interpretation of the data was done using a computer program (RES1D version 1.00.07 Beta). To interpret the data, some initial value parameters were found from the observed field curve and fed into the program. The initial value parameters were taken such that each points of maxima, minima and inflection indicate the existence of layer boundaries. The program uses these values to design a model curve, comparing it with the observed field resistivity curve. Where the modelled curve and the observed field curve are not in agreement, the initial value parameters were altered until the best agreement between the modelled curve and the observed field curve is obtained. At the point when the two curves were in best agreement and minimum error, the layer resistivity and thickness were recorded[8].

The geoelectric sections show the average variations of resistivity and thickness values of layers within the depth penetrated in the study area at the indicated sections. Generally, the sections revealed two to four subsurface layers: topsoil/laterite, indurated laterite, weathered and fresh basement layers. 


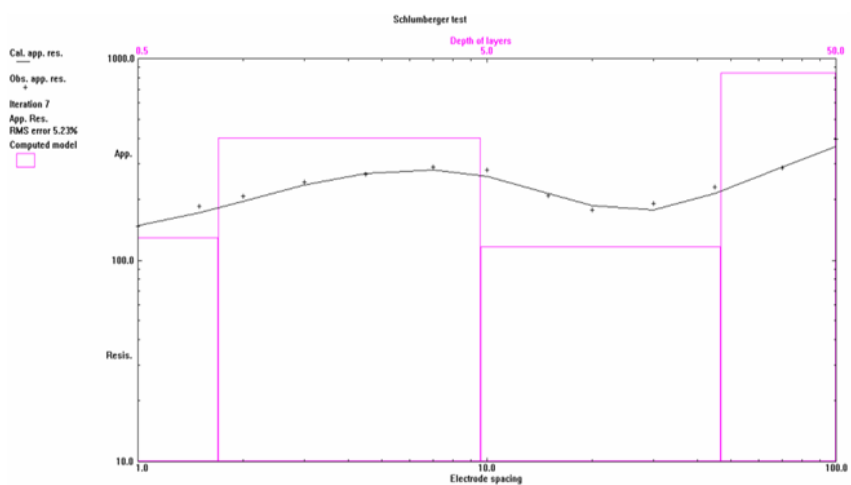

Figure 3. Typical resistivity curve.

\subsection{Data Processing}

Vertical Electrical Sounding (VES) data was collected on six (6) VES points using the Schlumberger configuration. The first stage in any interpretation of apparent resistivity sounding curves is to note the curve shape $[10,11]$. Before applying a more complicated method of interpretation, it is useful to consider a rough idea. The data collected in the study area were reduced and computed. The computed apparent resistivity values were then fed into a computer Geosoftware (ResID version 1.00.07 Beta) for resistivity curve interpretation. The interpreted data was used to generate the final model geoelectric parameters presented in Figure 3 which shows a typical example of resistivity curve.

\subsection{Resistivity Values}

Table 2 shows the resistivity range of geoelectrical layer compiled from some previous works around the study area.

Table 2. Resistivity values of some rock types basement area (compiled from $[1,2,3,9,10])$

\begin{tabular}{rr}
\hline Soil and Rock Types & Resistivity Value $(\Omega m)$ \\
\hline Fadama Loam & $30-90$ \\
Sandy Clay and Sandy Silty & $100-200$ \\
Sand and Gravel Laterite & $10-150$ \\
Weathered Basement & $20-200$ \\
Fractured Basement & $500-1000$ \\
Fresh Basement & $>1000$ \\
\hline
\end{tabular}

\section{Results and Discussion}

Results obtained indicates that the terrain is highly variable in thickness and resistivity. According to Alao[11] and Fadele et al. [12], the engineering competence of the subsurface can be qualitatively evaluated from the layer resistivity, since the higher the layer resistivity value, the higher the competence of the Layer.

The final model geoelectric parameters along the six VES stations were used for the preparation of the geoelectric/geologic

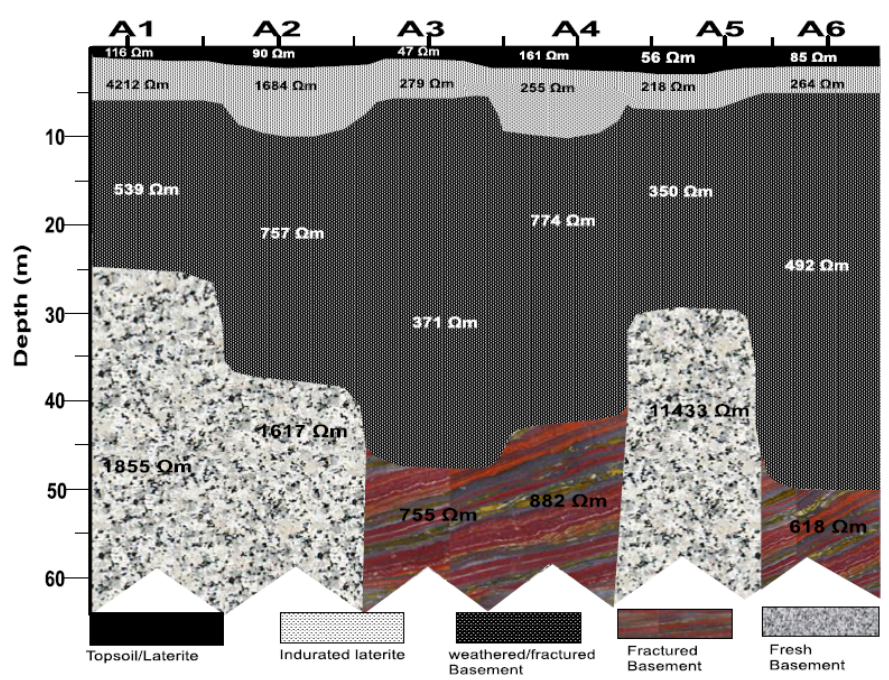

Figure 4. Shows the Geoelectric and Geologic section of the Study Area.

sections for one of the profiles (Figure 4). VES A1 is recommended for the construction of high-rise buildings, this is because the depth to basement is approximately $25 \mathrm{~m}$. Hence, the subsurface Layers at A1 are not favorable for groundwater exploitation. VES A3, A4 and A6 are not recommended for highrise buildings. However, surface Layers appear to be highly favorable for groundwater exploration which has the highest aquifer thickness of $46 \mathrm{~m}$ at a depth of $48 \mathrm{~m}$. This is because the thickness of the aquifer at this point ranges from $18 m$ to $42 m$ with a depth of approximately $6 m$ to $10 m$ respectively.

According to Aboh [1], the areas underlain with low bed rocks resistivity $(<1000 \Omega m)$ in Figure 4 could indicate fractures or faults. Hence, are less competent. Based on the resistivity values of the different geoelectric layers and the various geologic units obtained, the study has identified VES stations A1, $\mathrm{A} 2$ and A5 as competent zones. These regions were chosen due the fact that, there was no indication of geologic trend such as fracture or fault that could cause structure failure. Fadele, et al. [12], Dogara, et al. [13] and Alao [11], noted that the seasonal variation in the saturation of clay which causes ground movement could cause by clay swells and shrinkages; these factors could contribute to structural defect of building but the presence of consolidated laterite in the study area beneath the clayey topsoil which extends beyond $6.5 \mathrm{~m}$, could reduce the danger posed by clay formation to large buildings. However, the topsoil resistivity of the chosen zones is characterized with low resistivity and thin in thickness, which may not be good enough to support massive buildings. Hence, this superficial cover is loose humus/loam and clay formation at the topsoil in some part of the study area; thus need to be totally excavated in any future structural and engineering works. In summary, the interpreted data shows that there are no indications of any major trends such as fracture or faults in the area chosen as competent zones (A1, A2 and A5), that could aid building subsidence. 


\section{Conclusion}

The investigation shows the geo-electric and geologic sections derived from the study area which has revealed five subsurface layers, namely: lateritic topsoil followed by clayey/ sandy/ silty, layer, weathered basement and fractured/fresh basement rocks. A broad section of the area was classified as competent for civil works. There are no indications of any major linear structure such as fracture, faults or voids that could aid building subsidence in the study area.

However, the seasonal variation in the saturation of clay which causes ground movement could cause havoc in building construction due to the sensitiveness of soils to moisture loss or gain (swells and shrinkages) in VES A3 and A5. Considering the presence of consolidated laterite which extends beyond $3.0 \mathrm{~m}$ could reduce the danger posed by clay formation to large buildings as well as tarred roads. In summary, the interpreted data shows that there are no indications of any major trend such as fracture, cavities, voids or faults that could aid building subsidence in the area identified as competent zones. Other probable factors such tree roots, organic deposits, superficial cover that could cause foundation defects can therefore be eliminated by total evacuation of the topsoil.

The lithologies Thickness and Depth are as follows: Topsoil ranges from $1.0 m-1.8 m$; Indurated Laterite ranges from $1.9 m-6.8 m$; Weathered/Fractured Basement has infinite thickness. The Areas found to meet the conditions of high Basement resistivity and shallow Depth to Basement, are found to be at VES A1, A2, A3, A4 and A5. Hence, A1 have been found to be the competent zones within the Study Area, and are good for the construction of highrises, roads and bridges. VES A3, A4 and $\mathrm{A} 6$ those not meet the conditions for construction of highrises building. However, VES A3, A4 and A6 Areas appears to be very viable for groundwater exploration with aquifer thickness ranges from $18 m-42 m$ with depth ranges $6 m-10 m$. And the average Depth to Fresh Basement is $43 \mathrm{~m}$.

\section{References}

[1] H. O. Aboh, "Geotechnical characterization of surface materials in Kaduna Area, Kaduna State", Zuma Journal of Pure and Applied Science 4 (2002) 23.

[2] C. O. Ajayi \& M. Hassan, "The Delineation of Aquifer Overlying the Basement Complex in the Western Part of Kubani Basin of Zaria Nigeria", Journal of Mining and Geology 26 (1990) 117.

[3] N. Kure, H. O. Aboh, R. Jimoh, O. A. Joseph \& I. H. Daniel, "The Delineation of Potential Groundwater Aquifers within Basement Complex in ABU Zaria, Nigeria", British Journal of Applied Science and Technology 19 (2017) 1.

[4] E. M. Shemang, Electrical Depth Sounding of Selected Well Sites within the Kubani River Basin, Zaria, Nigeria, Unpublished MSc Thesis, Physics Department, ABU Zaria, 1990.

[5] O. Koefoed, "An appropriate method of resistivity sounding interpretation", Geophysical Prospecting 24 (1979) 617.

[6] M. O. Olorumfemi, S. A. Fasuyi, "Aquifer types and geoelectric/hydrogeologic characteristics of part of central basement terrain of Nigerian (Niger State)", Journal of Earth Science 16 (1993) 309.

[7] P. O. Udo, Physical geography of Nigerian, Heineman Education Publishers, 1982.

[8] K. M. Lawal, The application of reduction to the pole technique for the interpretation of aeromagnetic data of Zaria area, North Central Nigeria, 1998.
[9] N. K. Abdullahi, E. E. Udensi, A. Iheakanwa \& B. E. Eletta, "Geoelectrical method applied to evaluation of groundwater potential and aquifer protective capacity of overburden units", British Journal of Applied Science and Technology 4 (2014) 2024.

[10] M. W. Telford, L. P. Geldart, R. E. Sheriff \& D. A. Keys, Applied geophysics, Cambridge University Press, London, 1970.

[11] J. O. Alao, Delineation of the Interfacial Configuration in a Section of Millennium City, Kaduna, Unpublished MSc. thesis, Physics Dept. Kaduna State University, Kaduna, 2017.

[12] S. I. Fadele, S. B. Jatau, \& N. O. Patrick, "Geophysical engineering investigation around Makiyaye Village, shika area within the basement complex of North-Western Nigeria", International Journal of Engineering Research and Applications (2012) 1143.

[13] M. D. Dogara, J. Alao, H. Abdullahi, J. Ezekiel, J. George, \& R. A. Ahammed, "Delineation of the geotechnical parameters within the Kaduna refining and petrochemical corporation layout", World Journal of Applied Physics 2 (2017) 36. 